\title{
Teaching applied optics at the Univ. of Minho
}

\section{Manuel Costa}

Manuel Filipe M. Costa, "Teaching applied optics at the Univ. of Minho," Proc.

SPIE 2525, 1995 International Conference on Education in Optics, (13

October 1995); doi: 10.1117/12.224017

SPIE. Event: SPIE's 1995 International Symposium on Optical Science, 
Teaching Applied Optics at the University of Minho

\author{
Manuel F. M. Costa \\ Universidade do Minho, Departamento de Física \\ Tel. +35153 604327; Fax. +35153612367 \\ Email: mfcosta ci.uminho.pt \\ P-4709 BRAGA CODEX PORTUGAL
}

\begin{abstract}
In this communication we make a brief presentation of the branch of Applied Optics of the University of Minho's undergraduate course of Applied Physics.

The course of Applied Physics began in the year 1988/89. Previously we had just a course devoted to the formation of future physics and chemistry teachers at high school level. The Applied Physics course specialized in Optics appeared due to the growth of the physics department and due to request from the industry.

The Applied Physics course has two specialization's on the field of applied optics: Optometry; and Optics and Lasers.

The topics covered in the two first years of the course are common to the two branches. On the second semester of the third year the students must to choose between either one. The number of students on the Optometry branch was usually almost four times the number of Applied Optics and Lasers students. Nevertheless this tendency is rapidly changing. A short analysis of the results obtained will be presented focusing on last couple of years' advances.

Presented will also be the results of an inquest made on students' opinions about the quality of the course, and their own performance and expectations.
\end{abstract}

KEY WORDS: Education, Applied Optics, Physics, University

\title{
1. THE UNIVERSITY OF MINHO
}

The University of Minho is a 22 year old (created in August 1973) university located in the Portuguese north western' region of Minho ${ }^{1,2}$.

The University is distributed by two campus located in the two major towns of Minho: Braga the capital and important religious, cultural and commercial center, with the peculiarity of having a very young and active population (In fact Minho region is the one with higher percentage of youngsters in the 
European Community); and Guimarães the birth place of the Portuguese nationality almost nine centuries ago, is a major economic and industrial center (nevertheless let me stress that Minho was, and still is in a way, traditionally an agricultural region due to the fertile lands and very favorable climatic conditions). Plans exist to further spread the physical presence of the University in other towns.

The University is organized in organic units: six schools and institutes: sciences, engineering, economics, humanities, social sciences and education; nineteen research centers, and six cultural units (museums, libraries...).

In Braga are located the headquarters and the Science, Education, Arts, Economics and Management schools whose courses have around 8000 students. Most technological courses with around 3000 students are settled in Guimarães located $20 \mathrm{Km}$ south-east of Braga.

With a teaching staff of around 750 members, 41 undergraduate level courses and 48 master degree courses are established. More than 600 postgraduate students work here in full time.

\section{THE PHYSICS DEPARTMENT}

The physics department belongs to the School of Sciences (Physics, Chemistry, Biology, Mathematics and Earth Sciences). Our teaching and research staff of 42 full time members supported by 8 full time technicians, perform research, essentially applied, and teach around 500 physics students in two graduate courses and one Physics Education master.

Our research is made in four main subjects each one with different research groups:

Atomic and molecular physics: photophysical process in micro-heterogeneous systems; charge transfer in molecular systems; optical spectroscopy in condensed media; non linear spectroscopy studies of atomic relaxation;

Condensed matter: raman spectroscopy of metal oxide films; polymers study by raman spectroscopy; cooperative phases in polar dielectric; optical activity in phase transaction in dielectric; interface processes and models; phototermal spectroscopy;

Thin films and applications: study and production of corrosion resistant coatings; study and production of films for direct solar energy conversion; semiconductor thin films; ferroelectric thin films; plasma studies in magnetron sputtering systems;

Applied optics: optical bi-estability in microstructures; and, optical dimensional inspection of rough surfaces (where I belong and that aims the development of methods and optical coherent and incoherent systems able to perform the integral inspection of the micro-relief structures of different kinds of rough surfaces of interest specially on the industrial world. A method and system of dimensional surface inspection is on development in three basic versions: high resolution microtopographer; large distance 3D sensing; and a hand held height sensor).

The department's pedagogical activity apart from cooperation with other departments, the postgraduation and the graduate course of Physics-Chemistry, include a degree in Applied Physics with two specialization's on Optometry and Optics and lasers. 


\section{THE APPLIED PHYSICS GRADUATE COURSE}

\subsection{Introduction}

The growth of the Physics Department also in terms of scientific research activities in optics and the pedagogical prestige and good results obtained in the graduate course of Physics and Chemistry, created the conditions for the appearance of another graduate degree focused in optics.

The expansion of the optical components and optics related industries and moreover the growing need of optometry' technicians with university formation, lead to the creation of the course of Applied Physics (branch of optics) back in 1988.

\subsection{The course}

The course ("licenciatura") in Applied Physics ${ }^{3}$ has two specialization's: Optometry and, since 1990, Optics and Lasers.

After graduation the optometry students will have very good employment opportunities in the commercial sector of optometry and also in the ophthalmic lens and glass component's industry. In fact, to our knowledge, all of our students leaving the University (since 1993) have found readily a suitable job. About the students of the specialization in Optics and Lasers more difficulties are somewhat expected. Nevertheless their broad preparation will allow them to apply for a position in the industries of instruments and optical components, optical coatings, optoelectronics and photonics. Furthermore they will be able to enter the career of high school level physics teaching. A solid preparation in physics and mathematics with a good component of informatics is provided.

The "licenciatura" that has a duration of $41 / 2$ years is structurally divided in three parts:

the basic, common, set of disciplines taking fully the two first years and part of the third one;

the specialization matrices conformed by a set of optional disciplines divide in two main groups: optometry and optics and lasers;

one semester training period on the respective specialization domain.

Typically the academic year begins by the end of September and stops on the second week of January for the first term season of exams. Two opportunities are giving as for each class two exams are scheduled. The second term begins in February and ends by the end of May. It follows the second term exam's season. Another examination's season is provided in the beginning of September.

The two first academic years and the first term of the third year of the course are intended to provide a strong basic preparation on a broad band of subjects: mechanics, electromagnetism, thermodynamics, waves and physical optics, geometrical optics, electronics, quantum mechanics, atomic, molecular and solid state physics; mathematical analysis, algebra and analytical geometry, statistical and numerical methods; informatic applications and computer programming; general chemistry; technical drawing and technical english. 
From the third year a set of interdisciplinary optional disciplines is available providing a suitable specialized preparation. Specially on the branch of Optics and Lasers an important number of classes is implemented upon our research experiences: vacuum techniques and applications; characterization techniques, and non linear optics. The set of classes is completed with: image processing, fiber optics, lasers and applications, optical materials, technologies of optics, and transducers and data acquisition.

The course is completed with a six month training period either in the industry, on our laboratories or in foreign universities.

\subsection{The major problems}

Apart from problems at particular classes in specific conditions, the low high school preparation specially in mathematics and portuguese (they have important difficulties of expression) is a basic major constraint. This is recognized by the majority of student as one of the major constraints to the development of their studies.

Above these we must stress the very common lack of motivation. An inquest made recently shown that more than $50 \%$ of our student came to our course as second or third choice! Fortunately the degree of satisfaction concerning the course appears to be very positive in the end. Also the interest grows along the years and is reasonably high on the last year of the "licenciatura". Interesting its also to notice that around $60 \%$ of the students have a higher empathy with the applied optics' subjects then the other ones.

Another rather general problem concerns a certain lack of conscencialization by the students of the need of hard work. Hard work to meet the (theirs) goals. Often students tend to act very passively. When asked about what they sought is more important to a good learning, the clear explanation of the subjects or their own participation on the analysis of questions and problems, the choice was clearly (80\%) the first one. When asked the teacher should expect or demand an active participation of the students on class, the answer was also negative.

As a remark we also think that our students have a certain (certainly not natural!) lack of sense of enjoying learning. Nevertheless, if it is true that sometimes is not easy to make the students to be predisposed to have fun in class, the effort always pays and rapidly they tend to adhere with a nice result's improvement.

Each discipline is divided into three different classes: theoretical, theoretic/practical (problems) and laboratories. The theoretical classes are normally teach by the most experienced teachers hopefully holding a Ph.D. degree. He will be the full responsible for the discipline establishing the programs and coordinating the different classes. The theoretic/practical classes that usually take (as well as the other two) two hours per week, serve as a complement of the theoretical classes. Practical questions are analyzed and problems are solved, preferentially, by the students them self with teachers' coordination. The laboratorial classes, where the students must to perform typically simple experiments, are intended to give the students the opportunity to learn the use of important apparatus and to consolidate the knowledge given in the other classes.

Students' opinions about the different classes are revealing: $70 \%$ of them do not like the theoretical classes while only $10 \%$ think these are the most important ones; $56 \%$ feel the theoretical/practical classes to be the most important, and enjoy most the laboratories. 
To end up this short presentation let's indicate some other interesting results of the inquest (that where anonymous and not mandatory): the vast majority of the students (70\%) think that the role of the teachers is more important then the discipline's program or the work conditions, and do not distinguish between teacher's scientific and pedagogical aptitude; the majority say that they do study only on the vicinity of the exams and state that do not retain their acquired knowledge for long time...

\section{CONCLUSION}

Although its many limitations our students tend to enjoy their course of Applied Physics (branch of applied optics) and their employers do consider suitable or good the preparation of our ex-students.

\section{REFERENCES}

1. "20 anos de historia da Universidade do Minho", Braga (1994)

2. "Universidade do Minho - Guia 1993-94", Braga (1994)

3. "Livro de programas das disciplinas do Departamento de Física", Departamento de Fisica, Braga (1994) 